\title{
Assessing the quality of operation notes: a review of 1092 operation notes in 9 UK hospitals
}

\author{
Severn Audit and Research Collaborative in Orthopaedics (SARCO)
}

\begin{abstract}
Background: The General Medical Council states that effective note keeping is essential and records should be clear, accurate and legible. However previous studies of operation notes have shown they can be variable in quality and affect patient safety. This study compares the quality of operation notes against the National Standards set by the Royal College of Surgeons of England and the British Orthopaedic Association (BOA) for improving patient safety.

Methods: Information from Orthopaedic operation notes was collected prospectively over a 2-week period. All elective and trauma operations performed were included and trainees from the region coordinated data collection in 9 hospitals.

Results: Data from 1092 operation notes was reviewed. A number of important standards were nearly met including legibility (98.4\%), the name of the operating surgeon (99.3\%) and the operation title (99.1 \%). However a number of standards were not met and those with potential patient safety implications include availability on the ward (88.8\%), documentation of type of anaesthetic used (78.6\%), diagnosis (73.4\%) and findings (80.1\%). In addition, the postoperative instructions recorded the need for and type of postoperative antibiotics or venous thromboembolism prophylaxis in only $49.7 \%$ and $48.8 \%$ of cases respectively.

Conclusions: The quality and content of operation notes studied across the region in this period was variable. Use of software programmes in some hospitals for creating operation notes meant that some centres had better results for elements such as date, time and patient identification details. Following this study, greater awareness of the standards combined with additional local measures may improve the quality of operation notes.
\end{abstract}

Keywords: Operation notes, Medical record keeping, Orthopaedics

\section{Background}

Audits of operation note quality regularly identify failure to meet the required standards [1-5]. These worrying findings are often localised to individual specialities within different hospitals but can be seen as a snapshot of potentially more widespread problems. In 2009, the National Patient Safety Agency (NPSA) looked in detail at the causative factors in Patient Safety Incidents (PSIs) [6]. Human factors were a major contributor to PSIs and, in particular, communication problems were highlighted.

\footnotetext{
* Correspondence: jlrkblackburn@doctors.org.uk
Academic Clinical Fellow ST4 Trauma \& Orthopaedics, Musculoskeletal
Research Unit (MRU), Learning \& Research Building, Southmead Hospita

* Correspondence: jlrkblackburn@doctors.org.uk

* Correspondence: jlrkblackburn@doctors.org.uk
Academic Clinical Fellow ST4 Trauma \& Orthopaedics, Musculoskeletal
Research Unit (MRU), Learning \& Research Building, Southmead Hospital, Bristol BS10 5NB, UK
}

(c) 2016 Severn Audit and Research Collaborative in Orthopaedics (SARCO). Open Access This article is distributed under the terms of the Creative Commons Attribution 4.0 International License (http://creativecommons.org/licenses/by/4.0/), which permits unrestricted use, distribution, and reproduction in any medium, provided you give appropriate credit to the original author(s) and the source, provide a link to the Creative Commons license, and indicate if changes were made. The Creative Commons Public Domain Dedication waiver (http://creativecommons.org/publicdomain/zero/1.0/) applies to the data made available in this article, unless otherwise stated. aspects of error with illo habre instructions highlighted as common problems [7]. An operation note is an essential element of written communication in a patient's surgical pathway. The operation note, as with all clinical documentation, can prove vital in both the immediate care and safety of the patient as well as subsequent audit of care and sometimes, in medico-legal proceedings.

The Royal College of Surgeons (RCS) guidance, Good Surgical Practice with it's most recent version in 2014, dictates that surgeons must 'Ensure all medical records are legible, complete and contemporaneous' [1] and this guidance was endorsed by the British Orthopaedic 
Association (BOA). The General Medical Council (GMC) echoes this in Good Medical Practice 2013 [2]. Both the RCS guidance and subsequent BOA guidance, aimed primarily at documentation of total hip and knee replacement $[1,2,8]$, set out a number of criteria which must be met to constitute a safe and satisfactory operation note.

Improving the quality of communication among healthcare workers can help prevent errors [7]. Effective written communication should be accurate, clear, legible, comprehensive and contemporaneous [1].

The aim of this study was to compare the quality of elective and trauma Orthopaedic operation notes, across multiple centres, against the standards set by the RCS and the BOA.

\section{Methods}

The Severn Audit \& Research Collaborative in Orthopaedics (SARCO) is a trainee-led research collaborative that carries out multi-centre audits and research studies within the hospitals in the South West of England with the aim of improving patient care.

We prospectively collected Information from operation notes over a 2-week period at the end of January 2014 and included all operations performed in the Orthopaedic departments of 9 hospitals. We recorded demographic details including date of birth, gender and ASA grade for each patient, obtaining these from their medical record if not available on the operation note.

We assessed all operation notes against a core set of 29 standards, with a further 5 standards for knee replacements and 11 standards for hip replacements $[1,8,9]$ Tables 2 and 3.

\section{Results}

Nine units participated in the study, one of the units performed elective operations only with the remainder performing a mixture of elective and trauma procedures. A total of 1092 operation notes were included in the analysis and the demographics by unit and in summary are shown in Table 1.
The operation note was available on the ward following the return of the patient from the theatre unit in $87.8 \%$ of cases. The presence or absence of separate hand written postoperative instructions was not routinely recorded as this does not constitute part of the identified standards. Whether the procedure was performed as an elective or emergency procedure was recorded in $23.2 \%$ of cases $(0.5-52.3 \%)$ however one centre performed only elective procedures at the time of the study and when they are excluded this gives a mean of $32.3 \%$.

The percentage of operation notes containing the required information for the 29 core variables and the extra variables required for TKR and THR cases are shown in Tables 2 and 3.

A signature (defined as a hand written signature or an electronic signature that is uniquely linked to the signatory, which is capable of identifying the signatory, which is created using a means that the signatory can maintain under their sole control and which is linked to the data such that any subsequent change can be detected [10]) was present on $81.9 \%$ of operation notes studied (2.5-100 \%).

\section{Missing information}

Of the 29 standards for the core data set, only $2(0.2 \%)$ of the operation notes studied included data that met all of the standards. $139(13 \%)$ operation notes were missing between 0 and 4 items from the core data set, 643 (59\%) were missing between 5 and 9 items, 252 (23\%) were missing between 10 and 14 items and 58 (5\%) were missing 15 or more items (Fig. 1).

When the extra data required for a total knee replacement $(n=92)$ was considered, there were an additional 5 points of data required. None of the operation notes included all of these, 30 (33\%) of the operation notes were missing 1 item of data, 48 (52\%) of the operation notes were missing 2 or 3 items of data and $14(15 \%)$ were missing 4 or 5 items of data (Fig. 2).

When the extra data required for a total hip replacement $(n=114)$ was considered, there were an additional 11 points of data required (Table 2). None of the

Table 1 Demographics of included patients by centre

\begin{tabular}{|c|c|c|c|c|c|c|c|c|c|c|c|}
\hline \multicolumn{2}{|l|}{ Unit } & 1 & 2 & 3 & 4 & 5 & 6 & 7 & 8 & 9 & Total \\
\hline \multicolumn{2}{|c|}{ No. of operation notes } & 202 & 59 & 88 & 82 & 189 & 104 & 195 & 81 & 92 & 1092 \\
\hline \multicolumn{2}{|c|}{ Mean age (range) } & $59(18-91)$ & $58(20-96)$ & $65(18-96)$ & $53(4-91)$ & $56(4-96)$ & $56(5-91)$ & $59(4-92)$ & $67(18-102)$ & $59(11-99)$ & $59(4-102)$ \\
\hline \multicolumn{2}{|c|}{ Female gender (\%) } & $62 \%$ & $48 \%$ & $63 \%$ & $55 \%$ & $53 \%$ & $57 \%$ & $55 \%$ & $51 \%$ & $58 \%$ & $56.2 \%$ \\
\hline \multirow[t]{6}{*}{ ASA Grade } & 1 & $26 \%$ & $44 \%$ & $26 \%$ & $32 \%$ & $43 \%$ & $31 \%$ & $37 \%$ & $33 \%$ & $29 \%$ & $34 \%$ \\
\hline & $\|$ & $45 \%$ & $32 \%$ & $65 \%$ & $37 \%$ & $40 \%$ & $37 \%$ & $45 \%$ & $46 \%$ & $46 \%$ & $44 \%$ \\
\hline & $\|$ & $19 \%$ & $24 \%$ & $9 \%$ & $23 \%$ & $8 \%$ & $28 \%$ & $15 \%$ & $17 \%$ & $20 \%$ & $17 \%$ \\
\hline & IV & $1 \%$ & $0 \%$ & $0 \%$ & $9 \%$ & $0 \%$ & $4 \%$ & $2 \%$ & $4 \%$ & $2 \%$ & $2 \%$ \\
\hline & V & $0 \%$ & $0 \%$ & $0 \%$ & $0 \%$ & $0 \%$ & $0 \%$ & $0 \%$ & $0 \%$ & $0 \%$ & $0 \%$ \\
\hline & Not recorded & $9 \%$ & $0 \%$ & $0 \%$ & $0 \%$ & $9 \%$ & $0 \%$ & $1 \%$ & $0 \%$ & $3 \%$ & $4 \%$ \\
\hline
\end{tabular}


Table 2 List of 29 core standards, with comparison of handwritten and typed operation notes

\begin{tabular}{|c|c|c|c|c|c|c|}
\hline Core standards & Overall \% & Range & $\% \mathrm{~N} / \mathrm{A}$ & Handwritten \% & Typed \% & Chi-squared $p$ value \\
\hline 1. Available on ward & 87.8 & $44.3-100$ & - & 94.9 & 83.9 & $<0.0001$ \\
\hline 2. Date & 99.0 & $96.2-100$ & - & 98.8 & 99.5 & 0.185 \\
\hline 3. Time & 25.3 & $1.1-91.3$ & - & 19.4 & 36.5 & $<0.0001$ \\
\hline 4. Legible & 97.9 & $93.2-100$ & - & 96.5 & 99.8 & $<0.0001$ \\
\hline 5. Patient identifiers & 97.6 & $83.7-100$ & - & 95.7 & 99.8 & $<0.0001$ \\
\hline 7. Surgeon named & 99.3 & $96.6-100$ & - & 99.0 & 99.5 & 0.312 \\
\hline 8. Assistant named & 80.5 & 57.9-97.5 & 2.7 & 76.3 & 77.8 & 0.007 \\
\hline 9. Anaesthetist named & 79.9 & $42.4-95.2$ & 3.2 & 78.5 & 78.6 & 0.110 \\
\hline 10. Anaesthetic given & 60.9 & $35.6-85.2$ & - & 58.1 & 68.3 & $<0.0001$ \\
\hline 11. Consultant responsible & 73.6 & $37.1-97.6$ & - & 72.2 & 74.0 & 0.510 \\
\hline 12. Diagnosis & 76.3 & $57.6-98.8$ & - & 70.1 & 76.1 & 0.026 \\
\hline 13. Operation named & 99.2 & $97.4-100$ & - & 99.4 & 98.8 & 0.345 \\
\hline 14. Patient position & 56.8 & $37.3-77.8$ & - & 47.4 & 64.3 & $<0.0001$ \\
\hline 15. Incision/Approach & 90.0 & 76.7-98.8 & 1.4 & 86.1 & 93.2 & $<0.0001$ \\
\hline 16. Exposure & 52.8 & 18.6-73.9 & 4 & 52.1 & 53.4 & 0.75 \\
\hline 17. Elective/Emergency & 23.2 & $0.5-52.3$ & - & 30.1 & 23.5 & 0.015 \\
\hline 18. Findings described & 80.1 & $59.8-93.8$ & - & 68.9 & 88.6 & $<0.0001$ \\
\hline 19. Additional procedures performed and why & 50.5 & $27.1-75.0$ & 1.5 & 42.9 & 56.7 & $<0.0001$ \\
\hline 20. Tissue removed/added/altered & 62.0 & $31.7-87.7$ & - & 46.4 & 71.5 & $<0.0001$ \\
\hline 21. Prosthesis & 47.9 & $31.7-87.7$ & 41.1 & 43.4 & 47.6 & 0.209 \\
\hline 22. Serial no of prostheses & 18.1 & $0-72.8$ & 41.1 & 11.0 & 6.6 & 0.006 \\
\hline 23. Serial no of prostheses recorded elsewhere & 42.1 & $5.4-78$ & 41.1 & 37.2 & 42.5 & 0.224 \\
\hline 24. Complications described & 20.6 & $0-79$ & - & 16.6 & 18.2 & 0.486 \\
\hline 25. Closure & 81.0 & $7.6-97.5$ & 3.5 & 89.0 & 89.4 & 0.184 \\
\hline 26. Postop instructions & 97.6 & $89.4-100$ & - & 94.5 & 99.7 & $<0.0001$ \\
\hline 27. Antibiotics & 53.1 & $42.6-79.7$ & - & 48.7 & 50.6 & 0.530 \\
\hline 28. VTE prophylaxis & 50.6 & $40.9-67.8$ & - & 45.6 & 51.4 & 0.056 \\
\hline 29. Signature & 81.9 & $2.5-100$ & - & 95.1 & 60.2 & $<0.0001$ \\
\hline
\end{tabular}

operation notes included all of the data or was missing only 1 item of data, 13 (12\%) of the operation notes were missing 2 to 4 items of data, 86 (75\%) were missing 5 to 9 items of data and 15 (13\%) were missing 10 or more items of data.

\section{Preparation method for operation note}

Operation notes that were typed $(n=705)$ and those that were hand written $(n=387)$ were compared. Variables that were observed to be significantly different between these groups are shown in Tables 2 and 3 with associated $p$ values for the comparison.

\section{Discussion}

This audit represents the largest study of operation notes in the literature $(n=1092)$. It highlights the wide variability between individuals and institutions in the preparation of these notes. The study comprised solely of Orthopaedic procedures, both elective and trauma (emergency), and measured compliance with set standards $[1,2,9]$.

Some of the data points showed a high level of completion (>95 \%): legibility, patient identifier, date, surgeon and operation title. However there were also a large number of operation notes that lacked information that could potentially impact on patient safety. These include; availability on the ward (87.8\%), anaesthetic type $(60.9 \%)$, diagnosis $(76.3 \%)$, position of patient $(56.8 \%)$, exposure $(52.8 \%)$, findings $(80.1 \%)$, prosthesis name (47.9\%), complications $(20.6 \%)$, closure $(81.0 \%)$, antibiotics (53.1\%) and thromboprophylaxis (50.6\%).

It is possible some of the absent data points were omitted due to this information having already been present in the patients notes (e.g. diagnosis). Also it is likely that other omissions occurred due to the surgeon not recording negative factors, for example if no 
Table 3 List of TKR and THR extra standards, with comparison of handwritten and typed operation notes

\begin{tabular}{|c|c|c|c|c|}
\hline \multirow[t]{2}{*}{ TKR extras } & Overall & Handwritten & Typed & Chi-squared \\
\hline & $\%$ & $n=33$ & $n=59$ & $p$ value \\
\hline 1. Soft tissue releases & 66 & 21 & 40 & 0.686 \\
\hline 2. Bone grafting details & 4 & 0 & 4 & 0.126 \\
\hline 3. Component alignment/rotation & 70 & 29 & 35 & 0.004 \\
\hline 4. Flexion range & 55 & 18 & 33 & 0.898 \\
\hline 5. Tourniquet time & 83 & 27 & 49 & 0.881 \\
\hline \multirow[t]{2}{*}{ THR extras } & Overall & Handwritten & Typed & Chi-squared \\
\hline & $\%$ & $n=37$ & $n=77$ & $p$ value \\
\hline 1. Use of catheters/foot pumps etc. & 50 & 12 & 45 & 0.009 \\
\hline 2. Bone cement type & 59 & 25 & 42 & 0.186 \\
\hline 3. Cement insertion technique & 47 & 13 & 40 & 0.092 \\
\hline 4. Other implanted materials & 36 & 8 & 33 & 0.027 \\
\hline 5. Bone grafting described & 2 & 0 & 2 & 0.323 \\
\hline 6. Origin of bone graft & 2 & 0 & 2 & 0.323 \\
\hline 7. Drains/wound infiltration catheters & 18 & 3 & 17 & 0.066 \\
\hline 8. Instructions for drains/catheters etc. & 12 & 1 & 13 & 0.031 \\
\hline 9. Stability of joint & 67 & 33 & 52 & 0.013 \\
\hline 10. Sterile services tracking & 8 & 1 & 8 & 0.154 \\
\hline 11. Sterile services tracking details elsewhere & 61 & 22 & 51 & 0.480 \\
\hline
\end{tabular}

antibiotics were given it is possible the surgeon would not have stated 'no antibiotics' in the note. Other absent data may have been considered trivial, such as exposure for superficial incisions (e.g. during arthroscopy). However the majority of these data points should be recorded as a matter of course.

When looking at the extra data points required for knee arthroplasty notes there was a moderate level of completion with regards to soft tissue releases (66\%), alignment (70\%), flexion range $(55 \%)$ and tourniquet time $(83 \%)$. However all of these factors would have been performed intra-operatively and the completion of these surgical steps all have the potential to directly affect outcome and as such they should be included. Only $4 \%$ of notes commented on bone graft usage and this is likely to reflect the practise of not recording a step that was not carried out.

The additional data points for total hip arthroplasty showed wide variation. While hip stability was recorded the majority of the time (67\%), the usage of catheters/foot

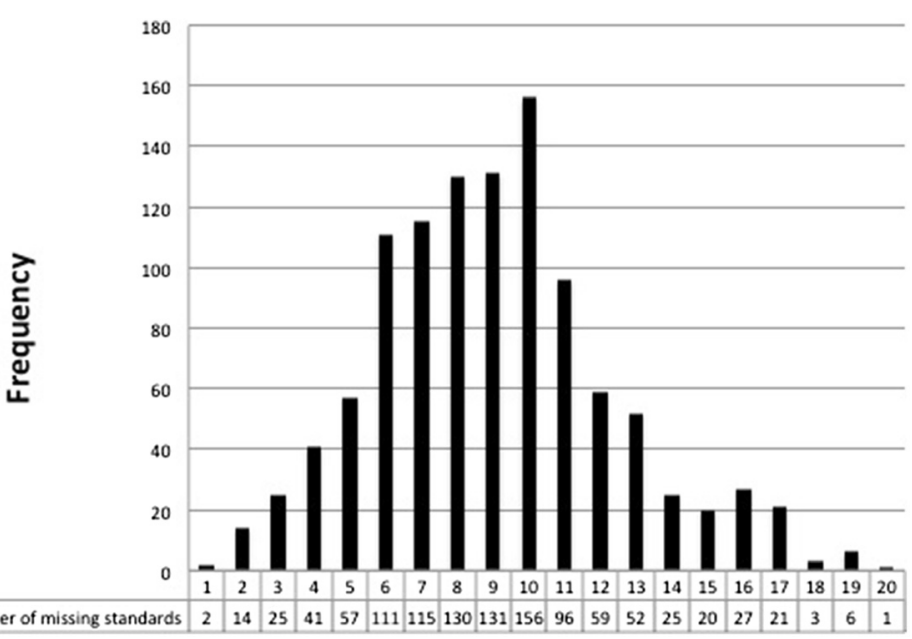

Fig. 1 Number of missing items from 29 core standards 


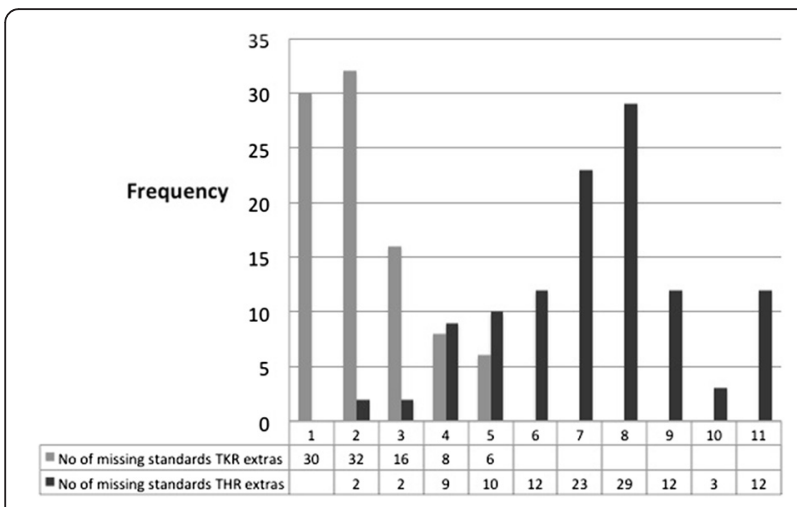

Fig. 2 Number of missing items from TKR and THR extra standards

pumps (50 \%) and other implanted material (36 \%) were generally poorly recorded.

Cement would not have been used in all cases, but cement type was documented in $59 \%$ and insertion technique in $47 \%$. Validation of the use or otherwise of cement during the total hip arthroplasty was beyond the scope of this audit. The recording of: use of bone graft $(2 \%)$, origin of bone graft $(2 \%)$, wound drains (18\%) and drain instructions (12\%) were infrequently found. However it may be that the surgeon felt that if they had not performed these steps (i.e. no drains/bone graft used) then the fact that they are not mentioned in the operation note means that they had not been performed. Clarity of communication to other members of the healthcare team may have been improved by recording negative variables that are part of the required standards.

It is important that the currently defined standards reflect contemporary practice, given the common use of uncemented implants in the NHS [11], the relative rarity of the use of bone graft in primary arthroplasty and the move towards not using drains in these procedures, the current standards may need revising or rewording to ensure that they are an aid to improved patient safety.

The finding that sterile services tracking information was not recorded in $39 \%$ of notes, despite almost certainly being confirmed by scrub staff prior to the operation, would be a potential cause for concern in the event of an infective complication, as there would be no evidence that appropriate sterility of instruments was checked in these cases. It is possible that this information was contained elsewhere in the medical record but it could not be found by the data collectors at the time of review of the medical notes on the ward following surgery.

There were several differences between those notes that were typed $(65 \%)$ and those that were hand-written (45\%). Hand-written notes performed significantly better in terms of availability, classification of procedure as emergency or elective, the presence of serial number of prostheses and a unique signature than typed notes
Table 2. For the TKR extras, handwritten notes were significantly more likely to record component alignment and for THR extras, the stability of the joint Table 3.

However typed notes were significantly better in most other standards including: patient identifiers, time of operation, legibility, naming of assistants, anaesthetic type, diagnosis, patient position, incision, findings, additional procedures performed, tissue removed or added, and post-operative instructions Table 2. Some of these elements may be better recorded if the system for generating the typed operation note includes computer generated elements such as time, date and patient identifiers. Other typed operation notes may be compiled using a template with prompts to include these standards.

For THR extra standards, typed notes were significantly more likely to record the use of catheters or foot pumps, details of other implanted materials and instructions for the use of drains or catheters Table 3.

Previous studies have highlighted the deficiencies in operative records. The 2003 NCEPOD Report [12] found that the ASA grade was not recorded in $33 \%$ of cases. Other studies have also found operation notes to be often below set standards [3-5, 13-16]. However many of these studies also found that highlighting the poor standard of notes, sometimes coupled with the provision of prompts and proformas, improved performance [3-5, 13-15]. Furthermore other studies have shown that typed or electronic operation notes improve the quality of data recorded as compared to hand-written notes [17-19]. One study also showed that completeness of data was further improved when electronic template notes were compared to typed dictated notes [20].

The NCEPOD report 1992/3 [21], noted the importance of being able to read and interpret surgical operation notes and stressed that poor record-keeping may impact on patient safety. When communication is ineffective or absent there a risk to patient care, for example if thromboprophylaxis is not requested as a postoperative instruction, any resulting delay in treatment may contribute to the development of a thrombosis or potential embolism.

\section{Conclusions}

This study shows that typed notes significantly improve the recording of intra-operative data, findings consistent with other studies [17-19]. Therefore adopting electronically typed, printed operation notes would improve the quality of note keeping, and if electronically stored and available to medical staff would also act as an easily accessible resource for use clinically, in audit and research as well as medicolegally.

However, within the region there are a number of types of typed notes including those created by proforma, those typed by the surgeon with a free text option and those typed from dictation. In some centres, trained clerical staff 
type dictated operation notes and may prompt surgeons to include important missing details in their notes.

Fortunately participation in this study has already improved awareness of the standards required from operation notes by a large number of trainees, and they are working within their respective hospitals to improve quality of both written and typed notes.

\section{Competing interests}

The authors declare that they have no competing interests.

\section{Authors' contributions}

The paper was prepared by JB, AS, NS, MW. All authors read and approved the final manuscript

\section{Acknowledgments}

Trainee collaborators from Severn Audit \& Research Collaborative in Orthopaedics (SARCO): Nathanael Ahearn, Sabina Barbur, Richard Barksfield, Laura Beddard, Julia Blackburn, Sarah Blake, Govind Chauhan, Daniel Constantin, Lucy Corbett, Nicole Corrin, lan Cunningham, Debashis Dass, Owain Davies, James Fletcher, Oliver Gosling, Andrew Grazette, Tom Hardy, Euan Harris, Lucy Hilder, Andrew Hughes, Ellen Jerome, Amy Lindh, Ben Marson, Queenie Pang, Greg Pickering, Marine Pitsika, Peter Robinson, James Smith, Damien Tucker, Abigail Ward, Hannah Wilson.

\section{Funding}

No funding used.

\section{Received: 3 September 2015 Accepted: 20 January 2016}

Published online: 06 February 2016

\section{References}

1. RCSEng. Good Surgical Practice. 2014

2. GMC. Good Medical Practice. 2013.

3. Payne K, Jones K, Dickenson A. Improving the Standard of Operative Notes within an Oral and Maxillofacial Surgery Department, using an Operative Note Proforma. J Maxillofacial Oral Surg. 2011;10:203-8.

4. Al Hussainy H, Ali F, Jones S, McGregor-Riley J, Sukumar S. Improving the standard of operation notes in orthopaedic and trauma surgery: the value of a proforma. Injury. 2004;35:1102-6.

5. Morgan D, Fisher N, Ahmad A, Alam F. Improving operation notes to meet British Orthopaedic Association guidelines. Ann R Coll Surg Engl. 2009:91:217.

6. Catchpole K, Panesar S, Russel J, Tang V, Hibbert P, Cleary K. Surgical safety can be improved through better understanding of incidents reported to a national database. Nat Patient Safety Agency. 2009.

7. Organisation WH. Patient Safety Workshop LEARNING FROM ERROR. 2008.

8. BOA/BASK. Knee Replacement: A Guide to Good Practice. 1999.

9. BOA/BHS. Primary Total Hip Replacement: A Guide to Good Practice. 2012.

10. Her Majesty's Stationery Office, Queen's Printer of Acts of Parliament. Electronic Communications The Electronic Signatures Regulations, S. Instruments. 2002.

11. National Joint W. Registry for England, Northern Ireland and the Isle of Man. 12th Annual. Report. 2015.

12. Cullinane M, Gray A, Hargraves C, Lansdown M, Martin I, Schubert M. The 2003 Report of the National Confidential Enquiry into Perioperative Deaths. 2003.

13. Bateman N, Carney A, Gibbin K. An audit of the quality of operation notes in an otolaryngology unit. J R Coll Surg Edinb. 1999:44:94-5.

14. Din R, Jena D, Muddu B. The use of an aide-memoire to improve the quality of operation notes in an orthopaedic unit. Ann R Coll Surg Engl. 2001;83:319-20

15. McGregor-Riley J, Ali F, Al Hussainy H, Sukumar S. Proformas can improve the quality of orthopaedic operation notes. J Bone Joint Surg. 2003;85:124.

16. Mathew J, Baylis C, Saklani A, Al-Dabbagh A. Quality of operative notes in a district general hospital: a time for change? Int J Surg. 2003;5:1-5.

17. Atrey A, Corbett S, Gibb P, Singh S, Jahnich H. Interactive computer operative notes for arthroscopy of joints: a free, accurate tool for surgeons. Arthroscopy. 2010;26:853-60.
18. Currall V, Chesser T. Computer generated operation notes. Stud Health Technol Inform. 2008;137:51-5.

19. O'Bichere A, Sellu D. The quality of operation notes: can simple word processors help? Ann R Coll Surg Engl. 1997;79:204-8.

20. Laflamme M, Dexter P, Graham M, Hui S, McDonald C. Efficiency, comprehensiveness and cost-effectiveness when comparing dictation and electronic templates for operative reports, AMIA Annual Symposium Proceedings. 2005. p. 425-9.

21. Campling EA, Devlin HB, Hoile RW, Lunn JN. The Report of the National Confidential Enquiry into Perioperative Deaths 1992/1993. London: NCEPOD; 1995. ISBN 0952206901.
Submit your next manuscript to BioMed Central and we will help you at every step:

- We accept pre-submission inquiries

- Our selector tool helps you to find the most relevant journal

- We provide round the clock customer support

- Convenient online submission

- Thorough peer review

- Inclusion in PubMed and all major indexing services

- Maximum visibility for your research

Submit your manuscript at www.biomedcentral.com/submit 